\title{
ORLANDO RIBEIRO, A UNIVERSIDADE E O ESPÍRITO CIENTÍFICO*
}

JOSÉ VEIGA SIMÃO ${ }^{1}$

A vasta e riquíssima obra de Orlando Ribeiro, que Suzanne Daveau, com amor, carinho e competência inigualável, vem revelando com proficiência e sem desânimo, constitui um domínio de estudo e de investigação, que engloba áreas do conhecimento que estão no cerne da construção de uma Europa Nova e da aposta no desenvolvimento humano, a nível mundial.

A figura de Orlando Ribeiro emerge como professor e investigador que ensina, confundindo-se na sua imagem o criador científico, o humanista, o construtor e visionário de organizações científicas de qualidade, o geógrafo do campo e da vida, o português do Mundo, o peregrino da ciência universal, o conselheiro de aventuras contra o arcaísmo e o imobilismo...

Perante este universo com que me defrontei, universo do saber, do saber fazer e do fazer, inquiri-me sobre como poderia tratar do tema por mim seleccionado, afinal contendo uma pequena parte, ainda que importante, da vida de Orlando Ribeiro - A Universidade e o Espírito Científico.

A forma rigorosa de proceder seria a de percorrer a sua obra e o seu curriculum, cronológica e serenamente, analisar e extrair dessa leitura as suas preocupações, ansiedades, revoltas e contentamentos, de modo a penetrar na evolução do seu pensamento e na incidência da sua acção, em múltiplos períodos da História recente, cheia de fenómenos sociais e culturais únicos, que atravessaram Portugal dos anos 30 aos anos 90 do século XX. Um trabalho que ficou por fazer mas cada vez é mais facilitado por Suzanne Daveau, ao publicar a Bibliografia Científica de Orlando Ribeiro, reeditando obras, que se não podem nem devem perder, muitas até agora inéditas...

Limitei-me, pois, a retirar as minhas próprias impressões, as que seleccionei como as mais salientes do seu pensamento. Uma atitude simplista e defensiva da minha parte, confesso, mas que só foi possível dada a coerência e consistên-

* Texto de uma conferência integrada num ciclo em torno da obra de Orlando Ribeiro, que teve lugar na Biblioteca Orlando Ribeiro, a 15/7/06. Recebido: 16/10/2007. Revisto: 23/01/2008. Aceite: 25/03/2008.

1 Professor Catedrático Jubilado. 
cia do pensamento científico de Orlando Ribeiro e da sua missão quase sagrada como professor e investigador ao longo de toda a vida. Orlando Ribeiro é, sempre, igual a si próprio. Este traço fortíssimo da sua personalidade ressalta com enorme fulgor de leitura do seu meio século de estudos geográficos e de vida científica e universitária.

Neste quadro, alerto essencialmente para recordações traduzidas em palavras de Orlando Ribeiro, com as quais me identifico.

Orlando Ribeiro é, sem dúvida, uma grande figura da Universidade e da Ciência. Desde muito novo que me senti seduzido pelos seus escritos, muitos dos quais me serviram como preciosas lições e sugestões para a minha acção cultural e política. No meu imaginário permanece como um grande senhor e um amigo de eleição. Nas suas confissões reveladas em 1986, nos Cinquenta Anos de Vida Cientifica e Universitária, Orlando Ribeiro testemunha que "um único Ministro me chamou um dia para me pedir informação e conselho sobre alterações que se estavam produzindo na Faculdade de Letras". E acrescenta, "numa conversa sincera e informal acabei por perguntar-lhe por que se tinha lembrado de mim", tendo-lhe eu respondido - "porque li coisas suas e sabia que se exprimia sempre com inteira sinceridade".

Eis o que eu pensava e o que me aproximava de Orlando Ribeiro.

Muito tempo decorreu sobre esses anos 70; porém, em todos os meus recentes escritos sobre ensino superior, ciência e tecnologia, inovação e competitividade tive em boa conta a frescura permanente que respiram os textos da obra de Orlando Ribeiro. Na verdade, guardo com carinho e supremo proveito, no meu pensamento, o seu contributo para diversas iniciativas da Reforma Educativa dos anos 70, onde emerge como símbolo do espírito científico e da ética universitária. Com esta atitude, que reside na minha alma, cumpro com alegria o dever de corresponder às palavras que me escreveu ao oferecer o seu livro Variações sobre Temas da Ciência, publicado em 1970, nas quais afirma a sua profunda adesão aos propósitos renovadores da Reforma Educativa que, segundo ele, "abalava estruturas, caracterizadas por um imobilismo de mais de quarenta anos".

Neste livro emerge, com força dominante, uma ideia-mestra sobre Orlando Ribeiro, formulada por Pascal: a de que toda a dignidade do homem está no pensamento. Em Orlando Ribeiro o pensamento flui como uma coisa admirável, nunca caindo nos excessos de excluir a razão ou de só salientar a razão.

E, assim, o seu espírito científico alerta-nos para uma postura que o vai caracterizar nos seus estudos e investigação:

"O mundo das ciências humanas, naquilo que é específico do homem, possui uma variedade que não se presta aos recursos de análises correntes nas ciências físicas. Por específicos do homem devem entender-se os fenómenos que decorrem da sua vida em sociedade e do poder criador do espírito e não, evidentemente, os caracteres da sua condição biológica, embora eles irrompam também no humano".

E acrescenta:

"Quando Vivaldi, baseado num conhecimento profundo da arte dos sons e no domínio dos instrumentos da orquestra, imaginou o desenvolvimento das formas 
de que saiu a música sinfónica, intitulou a principal colectânea das suas obras $\mathrm{Il}$ cimento dell'harmonia e dell'invenzioni, isto é, pôr à prova ou experimentar a combinação dos dois ingredientes fundamentais da criação musical. Deste ricercare de novas maneiras de exprimir sentimentos, impressões e ideias, podia parafrasear-se a essência da criação científica: a prova da observação e da invenção. Observação no seu mais lato sentido, do mundo exterior e interior, dos fenómenos espontâneos ou provocados, e que inclui, assim, tanto a percepção do real exterior ao homem como a vivência que este pode alcançar de si próprio e a repetição voluntária e vigiada - experimental, portanto -, no intuito de comprovar uma hipótese ou correlação explicativa. Invenção ou capacidade de imaginar relações, de aproximar o que aparentemente é diverso, de confrontar factos díspares à primeira vista e que à reflexão se podem revelar conformes entre si, encadeando-os numa sequência explicativa. Recursos de trabalho - por outras palavras, operações lógicas do espírito - que, afinal, estão subjacentes a toda a investigação científica".

Observação e invenção, articuladas em harmonia, são assim, no seu espírito científico, os ingredientes axiomáticos das actividades de Orlando Ribeiro.

Porém, como mestre experiente, adverte:

"Saber não é apenas desejar entender: é também possuir a consciência do mistério persistente que fica para além do que à razão se afigure claro e compreensível. A evidência - no sentido lato que a palavra tem na linguagem científica inglesa - talvez não seja mais que um "acidente" da essência. A evidência é o domínio próprio da Ciência; mas não é inútil, uma ou outra vez, reflectir sobre a natureza, o valor e as limitações desta forma de conhecimento. Nenhum ramo do saber dispensa a epistemologia: dela se pode tirar, pelo menos, perante os êxitos espectaculares da Ciência moderna, uma lição de humildade, proveitosa a quem for capaz de entendê-la (...).

Quando meditamos sobre estes e outros dos seus textos, sentimos a sua devoção à Ciência, conseguindo na vida um êxito natural, mercê de um travejamento firme, "conducente a construir ideias novas e trilhar caminhos de pesquisa, que ainda hoje vale a pena seguir". Nesse seu labor, o espírito científico que o domina é o da inquietação e da procura da excelência, convicto de que a homenagem ao passado significa que "se toda a Ciência houvesse de ruir seria decepcionante cultivá-la”. Nela há claridades que iluminarão para sempre. E é de acordo com esta profunda convicção que sustentou durante 50 anos o trabalho a que devotou a sua vida, em que, como nos confessa, comprometeu irremediavelmente a saúde, mas animado sempre de entusiástico esforço criador. Ao contrário do que nos quer fazer crer nas suas descobertas há "centelha de génio, como na música ou na poesia”. É que Orlando Ribeiro "cria, renova e traz ao espírito a luz do próprio reconforto".

A suprema lição a retirar é, pois, a de que, pela sua formação humana e científica Orlando Ribeiro, como nos ensinou Pascal, "sabe que a natureza se imita, que um grão lançado à boa terra produz, que um princípio lançado num bom espírito floresce. Os números apenas imitam o espaço e eles são de natureza muito diferente". 
É neste contexto que, obreiro de uma Escola de Humanismo e Ciência, de que o Centro de Estudos Geográficos é a sua prestigiada expressão universitária e científica, Orlando Ribeiro não se cansa de demonstrar por palavras e acções que respeita a liberdade de pensamento e fomenta o espírito autónomo e criador de seus discípulos.

Por isso afirma-nos com o vigor que lhe conhecemos: "Nunca procurei formar ninguém à minha imagem e semelhança e, se influenciei todos os que trabalharam comigo, deixei-lhes a maior liberdade de orientação dentro das exigências indispensáveis de rigor e reflexão. Uma escola científica não é repetição dos mesmos modelos, mas a arte de fazer com que cada um revele a personalidade mais adequada ao seu espírito, à sua formação e à própria alegria do trabalho pessoal".

E com a humildade dos homens de génio, pergunta: "Foi ilusão o ter conseguido os meus propósitos? Sempre procurei fazê-lo: a outros compete julgarem-me neste afã de consegui-lo".

No binómio, sempre permanente na sua acção, Universidade e Ciência, Orlando Ribeiro não deixa de alertar que a primeira deve cultivar a segunda, "com a ânsia de perenidade que inspira os artistas - da harmonia e do ritmo, da pedra e da cor, das grandes arquitecturas do som e da matéria" - como as sinfónicas na música, as metafísicas no pensamento, as arquitectónicas ou urbanísticas nos monumentos e nos arranjos, onde se verga o mundo aos anseios e necessidades dos homens. Aqui, explica-nos que "o Espaço, o Tempo e o Homem" são três domínios tanto de aquisições científicas como de diversos modos e instrumentos, sendo que o escopo de todo o pensamento científico é a exactidão.

Orlando Ribeiro, sem o confessar, vai assim cada vez mais longe nos seus textos, ao demonstrar que na prática cultivava já os valores do início deste milénio, tão bem expressos por Italo Calvino: a leveza, a rapidez, a exactidão, a visibilidade e a consistência. A leveza que se opõe ao poder de massas, dando predomínio na linguagem informática ao software, aos bits que comandam as máquinas; a rapidez, sabendo que a velocidade mental vale por si e como abertura à imaginação; a exactidão, que rejeita a linguagem descuidada, casual, sem fundamento; a visibilidade que resiste ao dilúvio de imagens erráticas e avulsas e faz da memória um depósito de lixo; a consistência, que associa o estudo e o engenho, coisas que juntas se encontram raramente, como nos diz o nosso Camões.

Ao ser pioneiro dum futuro do seu imaginário, recomenda-nos com a previsão de que é necessário ler o passado para fundar o futuro. Por isso sublinha que:

"É preciso que na Universidade se faça Ciência, porque daí devem resultar benefícios práticos para o País e porque cada Nação tem o dever de contribuir para manter e acrescentar o património espiritual da civilização em que se integra. Mas importa também que o espírito científico insufle um vigoroso impulso na educação da mocidade e na formação da elite nacional. A independência, a 
tolerância, a convicção, a tenacidade, qualidades indispensáveis ao trabalho científico, opõem-se ao desalento céptico, à carência de iniciativa, às parcialidades apaixonadas, aos entusiasmos sem persistência, que tantas vezes minam o carácter da juventude portuguesa".

"A actividade científica de um país - diz Orlando Ribeiro - manifesta-se de duas maneiras. Pela contribuição trazida pelos seus investigadores aos problemas gerais da Ciência e pelo estudo dos factos científicos de natureza regional, isto é, próprios do território, do povo, ou da língua desse país".

A este propósito diz-nos que a análise dessa contribuição torna patente o nosso atraso científico, transmitindo-nos o seguinte quadro:

"A investigação das nossas coisas é uma espécie de baldio aberto à curiosidade dos estudiosos de todo o Mundo. É certo que a Ciência não tem Pátria nem conhece fronteiras e muito nós devemos à colaboração de estranhos. Mas uma razão de dignidade nacional obriga a que os cientistas portugueses cubram com o próprio esforço o reconhecimento científico dos nossos territórios de três partes do Mundo. É preciso que um investigador estrangeiro, ao lançar as vistas curiosas para um tema português, encontre um terreno já demarcado por gente nossa, capaz de o iniciar, acompanhar e continuar e não apenas uma emaranhada selva de enigmas por onde vai marcar uma passagem episódica e isolada".

E aprofundando o seu pensamento:

"A Universidade carece de suscitar vocações científicas que se possam orientar, com segurança e eficiência, na investigação regional. O processo é um só: confiar o ensino a professores que investiguem, divulgar entre os estudantes o conhecimento dos métodos de pesquisa, conceder facilidades e promover estímulos para que os temas nacionais e a ilustração nacional de temas gerais, tenham o mais largo papel nos estudos universitários".

Não é aqui ocasião para fazer o meu depoimento de quanto Orlando Ribeiro me apoiou e incentivou com conselhos que guardo religiosamente, a desatar o nó cego resultante da existência de apenas quatro universidades no continente: duas em Lisboa, uma em Coimbra e outra no Porto. A este respeito registo estas palavras suas:

"As universidades novas têm de respirar desde a origem um ar lavado que lhes venha dos grandes centros científicos, fazendo-se largamente apelo a professores estrangeiros, quando não tivermos professores portugueses com categoria internacional. A mais elementar prudência manda criar, a pouco e pouco, os ensinos solicitados pelos estudantes e para os quais haja professores qualificados e não improvisados. É necessário que as novas universidades e escolas superiores não fiquem amarradas às categorias científicas tradicionais e que, num regime de maior liberdade de acção e organização dos institutos, venham a poder estruturar-se as faculdades doutro modo".

E conclui, traçando um caminho:

"Muito se poderia dizer sobre o assunto. Remato com uma reflexão e uma esperança: só as universidades novas poderão modificar as estruturas caducas e os vícios inveterados das universidades tradicionais". 
Orlando Ribeiro, um dos pioneiros na defesa das universidades novas, acompanhou a discussão das Linhas Gerais de Reforma do Ensino Superior com conselhos e escritos de valor indiscutível e foi um colaborador precioso no processo de decisão que conduziu à legislação e a medidas sobre expansão e diversificação do ensino superior em Portugal.

Hoje, ao lermos os documentos referentes ao debate nacional dos anos 70, sobre a Reforma Educativa e as opiniões por ele expressas, concluímos quão acertadas foram as decisões sobre a criação das Universidades do Minho, de Aveiro, Nova de Lisboa e de Évora e reconhecimento pelo Estado da Universidade Católica. E se perguntarmos qual o grau de sucesso destas novas instituições podemos afirmar que, apesar do caminho a percorrer, o balanço é notoriamente positivo.

Mas Orlando Ribeiro reflectiu noutros textos a clara noção dos perigos temporais para a Universidade que sonhou e não tem medo das palavras. Assim, em 1975, escreveu sobre "O Problema Fundamental da Universidade", cada vez mais longe de ser resolvido:

"Uma Universidade capaz de dar à nação a sua "inteligência", à ciência os seus investigadores, à tecnologia os seus agentes, ao ensino professores competentes e entusiastas, susceptíveis de moldarem o carácter e a compreensão dos adolescentes, tornando-os verdadeiramente aptos quer para continuarem estudando, quer para fazerem conscientemente alguma coisa de útil à sociedade. Os frustrados, os incapazes, os ineptos, os passivos absorvedores de sebentas, os que apenas vêem na escola um passatempo compatível com o seu nível social, nada aqui têm a fazer. A verdadeira Universidade não se faz com multidões, mas com gente rigorosamente seleccionada e apta. Apta a estudar e não, como agora se diz, apta a passar no exame".

Neste contexto, são ainda lapidares as palavras de Orlando Ribeiro em "Acerca da Orientação do Desenvolvimento Científico em Portugal":

"Se uma vez ou outra, a natural vivacidade da expressão chocou aqueles de cuja maneira de ver dissenti, desejava que ficasse dela apenas o apreço com que trago para a discussão ideias que não são as minhas. A Ciência foi, para mim como para tantos outros, escola de tolerância e de equidade. A clara consciência das limitações inevitáveis de qualquer formação científica, além das que me serão próprias e pessoais, levam-me a crer que outros possam apontar, ao problema que nos preocupa, soluções mais adequadas. Somente me propus trazer para o debate as que uma vida de reflexão me sugeriu".

"Amar e servir a Ciência - diz Orlando Ribeiro - no duplo aspecto da investigação e do ensino que, ao mesmo tempo, a divulga e alimenta, é no rumo que tracei, por dever de ofício e por convicção profunda, a maneira de promover, dentro dos escassos meios ao meu alcance, não apenas o progresso científico, mas a reforma da mentalidade do País".

Educação, Formação, Ciência, são preocupações centrais do professor universitário Orlando Ribeiro que nos anos 70 sentia, como o Ministro, a necessidade de uma Reforma Global do Ensino. E com essa visão, Orlando Ribeiro contribuiu notoriamente para o debate nacional sobre essa Reforma, que condu- 
ziu à aprovação da Primeira Lei de Bases que abrangeu a educação pré-escolar, todos os graus de ensino - básico, secundário e superior - e, ainda a formação profissional, sob o signo, ainda actual, de que "um cidadão mais culto é um cidadão mais livre".

Não é objecto deste artigo aprofundar a inestimável e lúcida cooperação sobre um novo modelo de ensino-aprendizagem para os sétimo e oitavo anos da escolaridade obrigatória e para os programas de ciências humanas e ciências da natureza nessa experiência pedagógica, que ele qualifica de "lufada de ar fresco". Não vou referir, igualmente, a sua cooperação na dinamização de uma política cultural ambiciosa e sobre uma nova conceptualização dos cursos das Faculdades de Letras. Direi apenas que o diálogo frequente que estabeleci em todos estes trabalhos e os alertas que me transmitiu sobre obstáculos que encontrava na sua implementação traduzem um inconformismo e um empenho, próprios de uma forma de cooperação baseada na frontalidade e no espírito de servir causas em que se acredita.

Porém, não podemos falar de Orlando Ribeiro como obreiro da Universidade e da Ciência sem referir o geógrafo eminente - o maior da ciência portuguesa, figura ímpar da geografia mundial. Assim o testemunham eloquentemente professores e investigadores nacionais e estrangeiros com mérito indiscutível.

Nestes breves apontamentos, consciente de que em vários fóruns e cerimónias lhe foi prestada a devida homenagem, direi só que a integração desta "coluna vertebral" do seu percurso, na visão global do pensador cientista e universitário, é magistralmente recordada em Originalidade da Expansão Portuguesa, livro publicado em 1994 e que colige escritos seus de 1962. Por ele se conhece esta vertente do seu pensamento científico:

"A expansão portuguesa figura entre os maiores acontecimentos da História Universal". No desenrolar da civilização europeia foi ela que, essencialmente "mudou o futuro do Mundo", tornando ubiquistas as suas formas.... "Se é certo que muitos aspectos da nossa expansão são bem conhecidos, se é facto que a erudição portuguesa dos últimos cinquenta anos se aplicou a esclarecer alguns deles, especialmente os problemas relativos às minúcias do descobrimento, à arte náutica, ao desenvolvimento da cartografia, ao reconto da história heróica dos portugueses no Brasil, na África e no Oriente, que podem considerar-se relativamente bem estudados, é verdade também que outros aspectos permanecem obscuros, que a muitas interrogações não se sabe o que se há-de responder e algumas dúvidas nem sequer se podem pôr duma maneira correcta que permita vislumbrar-lhes próxima solução. Tais são os problemas das origens da colonização e o problema dos instrumentos de fixação".

"O despertar da consciência africana, a formação de países novos nos limites de antigas colónias, teriam as mais tristes consequências se coartassem África ao homem branco. Uma vez mais a compreensão humana é necessária, passando por cima das culpas de todos, dos justos ressentimentos que são o reverso da medalha do desprezo e da humilhação com que tanta vez se continua a tratar gente de cor". 
"A pequena casa lusitana transformou-se hoje, na realidade, em um povo na terra. Mais de cem milhões de pessoas falam a nossa língua".

A riqueza de reflexões contidas neste livro permite-nos fortalecer a visão humanista, independente e generosa, talvez utópica, que a personalidade de Orlando Ribeiro representa e continuar a apostar no quadro do Portugal europeu, como mais valia a não ser perdida, nas consequências planetárias da formação progressiva do mundo luso-tropical, património espiritual de toda a Humanidade.

Orlando Ribeiro nunca esqueceu as obrigações de Portugal perante os novos países de língua portuguesa e por isso assumindo-se legitimamente como pioneiro na defesa da Universidade no Ultramar, diz em "Descolonização, Ensino e Ciência", em 28 de Outubro de 1974, no Diário de Notícias: "A emancipação progressiva do ultramar não nos dispensa, antes obriga a prosseguir a obra da educação e de pesquisa científica incrementada nos últimos anos".

A verdade é que Orlando Ribeiro e o Ministro se identificavam numa análise, a de que as universidades no Ultramar deveriam ter nascido dez anos antes, no início dos anos cinquenta.

Orlando Ribeiro, o universitário e o humanista, o cientista e o pensador, reserva para a sua "Geografia" um papel inserido na unidade teleológica do saber. E, por isso, não pode ser mais explícito na sua caracterização: "É, ao mesmo tempo, uma ciência de base e de convergência, um ponto de partida e um lugar de encontro: como uma encruzilhada, portanto, onde se chega e donde se sai por vários caminhos. O geógrafo sabe, como o naturalista, que o mundo físico e biológico está em perpétua transformação. Mas, comparado com a fugacidade de uma vida, ele é qualquer coisa que permanece".

Tem pois razão quando constata com orgulho: "Até à data, passaram pelo Centro de Estudos Geográficos da Universidade de Lisboa com mais ou menos demora: brasileiros, franceses, norte-americanos, alemães, um espanhol, uma dinamarquesa e uma holandesa; e não apenas geógrafos, pois etnólogos, soció$\log$ os e historiadores aí encontraram também condições de trabalho favoráveis".

É Orlando Ribeiro contra os hábitos de isolamento ou de rivalidade científica, procurando pôr em prática uma coisa de que se fala muito e se pratica pouco: a pesquisa "interdisciplinar" ou, pelo menos, "o alargamento de horizontes científicos pelas matérias em que, nas margens, alguns temas de estudo se recobrem".

A sua actividade foi um acto de fé na geografia universal e por isso afirma: "Com a consciência das próprias limitações, sem querer comparar-me aos grandes geógrafos do Mundo, eu que apenas falo baxo e rudo, recebi deles a luz forte da verdade e o sentimento das sombras que, num globo devassado por meios telúricos e cósmicos, não se esclarecem por enquanto".

Não encontro melhor fecho que o de Camões, português de profunda cultura humanista e científica e de anseios metafísicos que ao mesmo tempo a sustentam e limitam (Canto X dos Lusíadas): 
"Vês aqui a grande máquina do Mundo, Etérea e elemental, que fabricada Assi foi do Saber, alto e profundo, Que é sem princípio e meta limitado.

Quem cerca em derredor este rotundo Globo e sua superfícia tão limada, É Deus: mas o que é Deus, ninguém entende, Que a tanto o engenho humano não se estende".

Ao terminar estas breves reflexões, como notas soltas, não resisto, por razões óbvias, a deixar de mencionar uma analogia do geógrafo com o físico, uma analogia encontrada por Infeld e Einstein, na concepção complexa do que é um cientista: "Na tentativa de perceber a realidade, nós somos de certa forma como uma pessoa que tenta perceber o mecanismo de um relógio fechado. Essa pessoa vê o mostrador, os ponteiros e até ouve o tique-taque, mas não tem meios para abrir a caixa. Se o homem for engenhoso, pode imaginar um mecanismo que poderá ser responsável por tudo aquilo que observa, mas nunca poderá ter a certeza de que o mecanismo por si imaginado é o único que pode explicar as suas observações".

"Afinal, Infeld e Einstein descrevem o físico como um Sherlock Holmes moderno, usando o pensamento puro para ligar factos estranhos, incoerentes e sem qualquer relação entre eles. Por isso, por vezes, põe-se a tocar violino ou senta-se preguiçosamente no sofá a pensar e, de um momento para o outro, Eureka, faz-se luz".

Vale a pena ler e meditar sobre a obra de Orlando Ribeiro. Fornece-nos novas ideias e faz-nos luz sobre acontecimentos que vivemos e acicata-nos o espírito científico para a continuada e sempre maravilhosa aventura da descoberta.

Termino com palavras suas, proferidas quando recebeu, em 1988, o grau de Doutor Honoris Causa pela Universidade Complutense: "que não se apague a chama da Ciência que recebemos em nossa juventude e nos cabe legar, cada vez mais intensa e brilhante às gerações do futuro, vivat, floreat e creseat. 